\title{
THE ATTRACTIVENESS OF AUSTRALIAN EVENTS TO CHINESE VISITORS AND BARRIERS TO ATTENDANCE
}

\author{
LIZ FREDLINE AND XIN JIN \\ Department of Tourism, Sport and Hotel Management, Griffith Business School, \\ Griffith University, Gold Coast, Australia
}

\begin{abstract}
This article explores the attractiveness of Australian events to Chinese visitors. The Chinese have become the most important inbound market for Australia and this trend is likely to continue in the near future. Traditionally, Chinese visitors have been interested in sightseeing, but they are becoming more sophisticated in their travel behaviors and are seeking more active experiences. This exploratory study investigated whether Chinese visitors are attracted to events, what types of events they are likely to be interested in, and what factors impede their attendance at events based on data collected from Chinese tourists by travel agents in Guandong province. It was found that some Chinese tourists are interested in events, particularly festivals and cultural events, as well as certain hallmark sporting events. It was also found that interest in events appears to increase with travel experience, which bodes well for Australian events in the future as the Chinese travel market continues to mature. The findings will contribute a further cultural dimension to the event literature and help inform marketing and operations for individual events organizers and destination marketing associations.
\end{abstract}

\section{Key words: Chinese; Events; Attractiveness; Barriers}

Introduction

Events are heavily valued as attractions, catalysts, animators, place marketers, and image makers for destinations (Getz, 2008). As the events industry has grown, research on events has increased significantly. Well-researched areas include motivations and constraints for attendance (e.g., Crompton \& McKay, 1997; Dewar, Meyer, Li, 2001; Funk, Alexandris, \&
Ping, 2009; S.-K. Kim, Byon, Zhang \& Kim, 2013; X. Li \& Petrick, 2006; Santos-Lewis \& Moital, 2013; Van Zyl \& Botha, 2003), audience typologies and expectations (Mackellar, 2013), attendee experience (e.g., Robinson \& Clifford, 2012), events as destination image builders and marketers (e.g., Chan, 2015; Prentice \& Andersen, 2003; Richards \& Wilson, 2004), event evaluations (e.g., Getz, 2002; Williams \& Bowdin, 2007), and impact studies

Address correspondence to Liz Fredline, Department of Tourism, Sport and hotel Management, Griffith Business School, Business 2 (G27), Room 3.29, Gold Coast campus, Griffith University, QLD 4222, Australia. Tel: +61 75552 8697;

Fax: +61 75552 8507; E-mail: l.fredline@griffith.edu.au 
(e.g., Deery, Jago \& Fredline, 2012; Dwyer, Mellor, Mistilis, \& Mules, 2000; E. Fredline \& Faulkner, 2000; L. Fredline, Jago, \& Deery, 2003). Nonetheless, event tourism planning, development, and marketing remain a relatively unexplored research theme (Getz, 2008). With the exception of McKercher, Mei, and Tse (2006), few studies have focused their research on the attendance of international tourists at cultural and sports events. Therefore, the appeal, awareness, and barriers for event attendance from the perspective of international tourists is the topic of this exploratory research, and Chinese visitors to Australia are the subjects of this study.

China is one of the world's leading tourism source markets and the largest spender on international tourism (United Nations World Tourism Organization [UNWTO], 2016). Chinese outbound tourists usually travel for knowledge, relaxation, novelty, prestige, escape, and self-development (e.g., Hsu, Cai, \& Li, 2010). They value safety, quality of hospitality, and demand genuine respect (X. Li, Lai, Harrill, Kline, \& Wang, 2011). Common travel barriers for them include language barriers, safety and security risks (e.g., Sparks \& Pan, 2009), as well as cultural-, information-, and knowledge-related barriers (M. Li, Zhang, Mao, \& Deng, 2011).

China has become Australia's key source market in leisure travel in recent years. There were $6.8 \mathrm{mil}-$ lion international visitors to Australia in 2014. China contributed 789,300 visitor arrivals, ranked the second in total number of arrivals but first in terms of spending among all source markets of Australia (Tourism Australia [TA], 2014). With accumulated discretionary income from an increasingly larger body of middle class, with expanding travel aspirations, strong growth in Chinese demand is likely to continue (TA, 2014). China is expected to contribute about $24 \%$ of the increase in inbound arrivals from 2013 up to 2023, and about 40\% in tourist expenditure (TA, 2014), making China the most important source market for Australia.

Both sports and cultural (including musical) events are important components of the Australian economy, in terms of employment, the supporting industries, sales of goods and services both within and beyond Australia, and small business development. Tourism Research Australia conducts an International Visitor Survey each year, and their TRA Online Student Data tool reports that over the 5-year period from 2011 to 2015, approximately 8.8\% of Chinese visitors to Australia have attended festivals, fairs, or cultural events.

With regard to destination marketing, TA has made a shift from selling products to selling experiences to international visitors and has been facilitating tourism businesses to do so. However, a brief look at the current websites of federal and state tourism bureaus gives the impression that unique Australian experiences were mainly interpreted as experiencing Australia's unique nature/wilderness/outback scenery and landscape, marine activities, and food and wine. Various types of events were not promoted as a key component of unique Australian experiences. Although The Tourism Australia Act 2004 outlined the requirement for TA to establish a division to concentrate on the business and major events sectors (Stokes, 2008), this division Business Events Australia basically promote the business events sector. Promotion of Australia's nonbusiness events is not prominent. The question arises as to whether it is because international tourists are not interested in experiencing nonbusiness events, or is it because international tourists lack the knowledge of these events and find them difficult to access?

This study thus aims to explore the attractiveness of Australian nonbusiness events to Chinese visitors. Here, event attendance/participation can be a supplementary or complementary motivation or activity during their trips. The study aimed to explore the following issues: 1) Are Chinese visitors interested in experiencing nonbusiness events if they travel to Australia?; 2) What types of events are they interested in?; and 3) What are the barriers for their attendance? This is the first empirical investigation of the attractiveness of Australian nonbusiness events to Chinese visitors and therefore is highly exploratory. The findings contribute to both knowledge building in event studies and event and destination marketing and operations for event organizers and destination marketing associations.

\section{Literature Review}

\section{The Nexus of Tourism and Events}

The nexus of tourism and events-events tourism-has been described as "the planning, development and marketing of events as tourist 
attractions to maximize the number of tourists participating in events as either primary or secondary attractions" (Getz, 1997, p. 16). Events can be important tour motivators and are increasingly important for destination competitiveness (Getz, 2008). The interest in events tourism has been propelled by the growing international trend of utilizing major events and festivals as tourism generators (Getz, 1997; Gnoth \& Anwar, 2000; Robertson \& Guerrier, 1998).

Events could be viewed as one of the tourist attractions within the tourism attraction system (McKercher et al., 2006). Although visits to core attractions satisfy a primary travel motivation, visits to secondary/peripheral attractions are typically the result of low involvement purchase decisions, convenience, or coincidence. In making a decision on which attractions to visit, certain formal or informal assessments of the benefits of participation are made, and the final decision could be a trade-off of one event against another that is felt to be of greater value (McKercher et al., 2006). Mega-events serving as important motivators of tourism activity could be regarded as core attractions (Kruger \& Saayman, 2012; Regan, Carlson, \& Rosenberger, 2012; Savinonic, Kim, \& Long, 2012). However, research on whether hallmark or regional events function as core or peripheral attractions is scant.

Events have increasingly become part of the destination marketing schemes, as the image of events a destination hosts will affect the image of the destination based on how congruent the images are (Chalip, Green, \& Hill, 2003). In Australia, the structures for event development and related tourism marketing are complex and institutionally deep rooted (Stokes, 2008), with major constituting organizations being state tourism bureau, events agencies/divisions, city agencies, and sports departments. Australia is viewed as one of the leaders in event and tourism comarketing; yet, few destinations have tangible event tourism strategies (Stokes, 2008). Reasons for this could be speculated from knowledge gained from event literature that draws findings from different kinds of events. For example, many festival organizers do not see festivals as money-making tourist attractions, rather as an enjoyable community-based events (De Bres \& Davis, 2001). Many planned events are produced with little or no thought given to their tourism appeal or potential (Getz, 2008). Arts festivals in particular display a lack of concern for tourism and take a product orientation that tends to ignore customer needs and commercial realities (Getz, 2008). It could also be that event organizers do not invest heavily in marketing the event to culturally and geographically distant attendees based on the understanding that cultural distance would decrease the likelihood of event attendance. Indeed, not all festival attendees are motivated to visit the destination to participate in the festival, but a prestigious cultural event such as the Edinburgh International Festival attracts a large number of international attendees (Prentice \& Andersen, 2003).

Whether the cultural element of events either attracts or deters international visitors is an important but underresearched topic. Many festivals are rooted in local traditions and can serve as a signifier of the "otherness" and "exoticness" of a destination (McKercher et al., 2006). As embodiment of local culture and customs that highlight a destinations' cultural uniqueness, festivals could provide a powerful experience to tourists. However, in many cultural events the presence of international tourists is very limited. Among the two possible reasons for low attendance of international tourists, namely events lacking intrinsic tourist appeal and events being ineffectively marketed, the latter appears to be the major obstacle inhibiting international tourists' participation (McKercher et al., 2006). Nonetheless, few empirical studies have explored the awareness, appeal, or barriers for international tourists to attend cultural and sports events.

\section{Motivation and Barriers to Attend Events}

Motivation research in the event sector is well established (Dewar et al., 2001, Getz, 2008). Motivations to attend events have been investigated using the push and pull approach. For example, pull motivations for art festivals usually include entertainment, music, celebrities, the variety of activities, and food \& beverage offered (Van Zyl, \& Botha, 2003); while push motivations to festivals are found to be socialization, being with family, novelty, escape from daily life, and excitement of the event itself (Bowen \& Daniels, 2005; K. Kim, Uysal, \& Chen, 2002). Iso-Ahola’s (1983) seeking and escaping theory is also largely confirmed in the 
events motivation context (X. Li \& Petrick, 2006). Visitors may seek symbolic significance in events attendance where they can be associated with selfesteem and community pride (Van Zyl \& Botha, 2003). Curiosity (Dewar et al., 2001) and attendees' interest in event theme, event atmosphere, and welcoming feelings showed by the local people are also motivational factors (Pegg \& Patterson, 2010).

Visitor motivations are classified according to personal, social, and physical contextual characteristics (Axelsen, 2006). Personal context involves learning and education, novelty, previous experiences, professional interest, and specific interest. Social context includes social experiences, cultural experience, family togetherness, recommendations from internal and external sources, and special learning experiences. Physical context mainly includes the event package, event type, quality, and event atmosphere (Axelsen, 2006). An event can put the attendee to extremes of emotional or physical experience leading to greater self-knowledge and a rite of integration, where interaction with the others consolidates shared cultural values and introduces a temporary sense of closeness (Morgan, 2009). Thus, personal benefits (e.g., enjoyment, socializing, self-development), social interaction, a symbolic meaning derived from identification with the meanings, and values of the event have been emphasized (Morgan, 2009).

Unique and attractive positioning makes a festival successful (Getz, 2002), which includes artists performance (Bowen \& Daniels, 2005), the authenticity of the cultural experience (Matheson, 2005), and the location's natural or cultural heritage and community pride (Van Zyl \& Botha, 2003; Xie, 2004). Based on motivational factors, market segmentation studies have been conducted, giving indications in differentiation of promotional strategies. For example, in festival market, the domestic attendees could be influenced by TV and radio, whereas foreign visitors could be influenced by friends and travel agency (Lee, Lee, \& Wicks, 2004). However, given the highly exploratory nature of the current study, detailed investigation of motivations and market segments is premature.

Few studies have examined the barriers to event attendance (Deery, Jago \& Fredline, 2004; SantosLewis \& Moital, 2013). Nonattendance to special events is related to demographic and family lifecycle-related factors, in addition to psychographic variables, including lack of time, lack of interest, and dislike for crowds (Milner, Jago, \& Deery, 2004). Common leisure constraints include time, money, health, emotional attachment, social relationships, and travel distance (Boo, Carruthers, \& Busser, 2014). Event attendance being time consuming has been emphasized by several studies, as usually it requires a full day's time investment for attending most of the festivals (McKercher et al., 2006). Motivation (e.g., anticipated interest, thrills, and enjoyment) could be a countervailing force to constraints that promoted attendance (Funk et al., 2009). Other constraints were event atmosphere and lack of team attachment (Pritchard, Funk, \& Alexandris, 2007) and gaps in cultural values and norms (Lepisto \& Hannaford, 1980). An individual's specialization level in a given recreational activity might predict event attendance of the individual relevant to that activity (Santos-Lewis \& Moital, 2013). Thus, a set of intrapersonal, interpersonal, structural, time, and financial constraints are identified that affect festival attendance (Boo et al., 2014). However, very few festival and sports studies investigated the perceptions of international attendees/tourists.

\section{Methods}

\section{Sample and Sampling Procedure}

The target population for the study was potential Chinese visitors to Australia. A suitable respondent was defined as any individual aged 18 or older who was financially and physically capable of making international trips. The survey of Chinese visitors to Australia was administered through Chinese travel agents based in Shenzhen, which is an economically leading city in China, located in Guangdong province and adjacent to Hong Kong. Guangdong province has had the strongest GDP output in China for a consecutive 28 years, with a GDP exceeding 7.9 trillion yuan (US\$1.15 trillion) in 2016 ("Guangdong's Economy Remains Biggest,” 2017). It is one of the three leading source markets for Chinese outbound travel-the others being Shanghai and Beijing (China Tourism Academy [CTA], 2014). Travel agents and tour leaders who agreed to help with the survey distributed the 
questionnaires to tourists who enrolled in their package tours, including tours to both domestic and overseas destinations. This face-to-face survey method was considered more reliable and effective than surveys conducted in streets or shopping malls, or using an online survey approach, because the respondents enrolled in package tours were actual tourists and therefore potentially in the market for an Australian holiday. Although some tourists might not have been to overseas destinations, the probability for them to travel overseas in the future is higher than that for the general Chinese population. To a certain degree, respondents residing in Guangdong province and sampled via travel agents during their domestic and overseas trips could be regarded as a valid sample of potential Chinese outbound tourists to either Australia or other overseas destinations. The survey was conducted over a 1-month time period in July 2014; 400 questionnaires were distributed and 335 valid responses were collected.

\section{Instrument}

This study treats events as one type of tourist attraction, so as to assess the attractiveness of Australian events to Chinese visitors in comparison to the other activities they could participate in. The first section of the questionnaire assessed the likelihood of participation in different tourist activities using a list of 25 activities based on the International Visitor Survey conducted annually by Tourism Research Australia. This measure uses a 5-point Likert scale, where 1 = very unlikely, $3=$ neutral, and $5=$ very much likely. The second section asked respondents to rate their level of interest in attending events broken down by types of events (ticketed vs. nonticketed, sports, festivals, and food \& wine events) again using a 5-point Likert scale, where 1 = not at all interested, $3=$ neutral, and $5=$ very much interested. The third section lists 13 specific events promoted by federal and state tourism bureaus on their websites, held in various months of a year, including Sydney New Year Eve Fireworks, Australian Open Tennis Tournament, Tour Down Under (cycling event), Australian Open of Surfing, Australian Formula 1 Grand Prix, Melbourne Comedy Festival, Sydney Royal Easter Show, Gold Coast Marathon, City to Surf Fun Run, Floriade Flower Festival, Gold Coast 600 Motor Race, and Melbourne Cup House Race. Locations and months of these events were provided in the questionnaire as many respondents were unlikely to be familiar with them. An additional option (i.e., don't know) was added to the 5-point Likert scale (where 1 = not interested at all, $3=$ neutral, and $5=$ very interested) used to evaluate respondents' interest in these events. The next section asked respondents to evaluate 11 barriers that reduce their interests in attending events on a 5-point Likert type scale, where $1=I$ would not want to attend because of this issue, $3=$ neutral, and 5 = I would still like to attend despite this issue. Typical travel constraints such as insufficient time and money were not included because the sample was based on customers of travel agents who had visited the agent to book travel. Therefore, it was assumed they had sufficient time and money to do so. Other information collected included: gender, employment status, year of birth, self-reported English language proficiency, number of times of traveling abroad, continents visited, top three preferred continents for international travel, and intention to travel to Australia in the next 3 years.

\section{Data Analysis Methods}

A range of analyses incorporating frequencies, descriptive analysis, exploratory factor analysis, ANOVAs, and cluster analysis were completed using SPSS version 22.0. Data were cleaned before analyses by deleting any cases with more than $10 \%$ missing values as well as cases with inconsistent answers or evidence of response set (e.g., only ticking extreme or midpoint values). This resulted in 335 valid responses. In dealing with missing values, the listwise deletion method was used for descriptive statistics. Where a small number of missing values were observed in the interest scales, it was inferred that a missing response equated to "no interest" and the missing values were replaced a 1 for the exploratory factor analysis and cluster analysis.

\section{Results}

\section{Respondents' Profile}

The sample was dominated slightly by female and younger tourists. About $60 \%$ of respondents 
were female. In terms of age, about $22.8 \%$ of respondents were above $36,48.9 \%$ between 26 and 35, and $24.3 \%$ between 18 and 25 . Half of the respondents were born in the 1980s, which is a distinctive generation in China with unique characteristics (Yang \& Lau, 2015). This is also the emerging source market for Chinese outbound tourism. About $70 \%$ of the respondents indicated that they could understand or speak a little English. Around 14.6\% of respondents reported they could communicate in English with native speakers. In contrast, only $13.7 \%$ claimed that they did not understand English at all. The respondents could be regarded as relatively experienced travelers within the Chinese outbound market as the majority (74\%) had traveled overseas previously (and, in the context of this research, overseas destinations did not include Hong Kong and Macau). The highest incidence of overseas travel by any individual was reported as 25 trips. The most visited destinations were Southeast Asia (186 visits), Australia (59 visits), Europe (56 visits), and Northeast Asia (49 visits). This is consistent with the most popular destinations for Chinese outbound tourists as reported by CTA (2014). Australia/New Zealand were also popular destinations for future trips-ranked second as the first most wanted to visit destination and ranked first as the second preferred destination. This is consistent with CTA reports (CTA, 2014) with regards to most popular long-haul destinations for Chinese outbound tourists. About $36 \%$ of the respondents would be likely to visit Australia within 3 years (Table 1).

\section{Likelihood of Participation in Types of Activities}

Respondents' likelihood of participation in different types of activities was analyzed using mean values and exploratory factor analysis (Table 2). Among the 25 activities, "go to the beach," and "whale/dolphin watching," were the only two items with a mean above 4 (on a 5-point scale). However, "sightseeing of a city," and "eat out at a restaurant/café," "swimming," and "shopping” also had high mean values, which was an indication of a high likelihood of participation in these activities. The next tier of preferred activities included festivals/cultural events, visit outback, visit farms, experience aboriginal culture,
Table 1

Respondents’ Profile

\begin{tabular}{|c|c|c|}
\hline & Frequency & $\%$ \\
\hline \multicolumn{3}{|l|}{ Gender } \\
\hline Female & 202 & 60.3 \\
\hline Male & 131 & 39.1 \\
\hline \multicolumn{3}{|l|}{ Age } \\
\hline Before 1969 & 19 & 5.7 \\
\hline 1970-1979 & 57 & 17.1 \\
\hline 1980-1989 & 163 & 48.9 \\
\hline 1990-1995 & 73 & 21.9 \\
\hline 1996 & 8 & 2.4 \\
\hline \multicolumn{3}{|l|}{ English proficiency } \\
\hline Speaks a little & 131 & 39.1 \\
\hline Understand a little but cannot speak & 105 & 31.3 \\
\hline Doesn’t understand at all & 46 & 13.7 \\
\hline Can communicate with natives & 41 & 12.2 \\
\hline Fully proficient & 8 & 2.4 \\
\hline \multicolumn{3}{|l|}{ Employment status } \\
\hline Employed & 276 & 82.4 \\
\hline Self-employed & 18 & 5.4 \\
\hline Student & 15 & 4.5 \\
\hline Other & 12 & 3.6 \\
\hline Retired & 5 & 1.5 \\
\hline \multicolumn{3}{|l|}{ Times travelled overseas } \\
\hline 0 & 87 & 26 \\
\hline 1 & 58 & 17.3 \\
\hline 2 & 63 & 18.8 \\
\hline 3 & 42 & 12.5 \\
\hline $4-25$ & 60 & 18 \\
\hline \multicolumn{3}{|l|}{ Overseas destinations have visited } \\
\hline Southeast Asia & 186 & 55.5 \\
\hline Australia & 59 & 17.6 \\
\hline Europe & 56 & 16.7 \\
\hline Northeast Asia & 49 & 14.6 \\
\hline Middle east & 31 & 9.3 \\
\hline North America & 19 & 5.7 \\
\hline South America & 7 & 2.1 \\
\hline \multicolumn{3}{|l|}{ 1st preferred overseas destinations } \\
\hline Europe & 164 & 49 \\
\hline Australia/NZ & 86 & 25.7 \\
\hline North America & 33 & 9.9 \\
\hline \multicolumn{3}{|l|}{ 2nd preferred overseas destinations } \\
\hline Australia/NZ & 104 & 31 \\
\hline Europe & 77 & 23 \\
\hline North America & 60 & 17.9 \\
\hline \multicolumn{3}{|l|}{ Likelihood to visit Australia in 3 years } \\
\hline Neutral & 109 & 32.5 \\
\hline Very likely & 84 & 25.1 \\
\hline Likely & 39 & 11.6 \\
\hline Not at all likely & 49 & 14.6 \\
\hline Not likely & 38 & 11.3 \\
\hline
\end{tabular}

Note. Listwise deletion was used in frequency analysis; thus, the total number is not consistent to the sample size number. 
Table 2

Activities: EFA

\begin{tabular}{|c|c|c|c|c|c|c|c|c|}
\hline & Mean & $S D$ & $\begin{array}{l}\text { Factor } \\
\text { Loadings }\end{array}$ & 1 & 2 & 3 & 4 & Communalities \\
\hline Cultural activities & 3.66 & & & & & & & \\
\hline Theater/concerts/performing arts & 3.57 & 1.325 & 0.722 & 0.181 & 0.286 & 0.093 & 0.131 & 0.622 \\
\hline Museums/art galleries & 3.46 & 1.319 & 0.707 & 0.235 & 0.289 & 0.034 & 0.252 & 0.703 \\
\hline Experience aboriginal culture & 3.74 & 1.209 & 0.692 & 0.216 & 0.161 & 0.127 & 0.089 & 0.576 \\
\hline Festivals/cultural events & 3.73 & 1.298 & 0.686 & 0.125 & 0.276 & 0.081 & 0.291 & 0.653 \\
\hline Visit farms & 3.72 & 1.325 & 0.621 & 0.509 & 0.057 & 0.159 & -0.046 & 0.675 \\
\hline Historical buildings/monuments & 3.72 & 1.221 & 0.597 & 0.115 & 0.054 & 0.022 & 0.477 & 0.600 \\
\hline Popular tourist activities 1 & 3.78 & & & & & & & \\
\hline Sightseeing/looking around inside a city & 3.95 & 1.19 & 0.129 & 0.653 & 0.131 & 0.002 & 0.416 & 0.633 \\
\hline Bushwalking/rainforest walks & 3.62 & 1.302 & 0.205 & 0.651 & 0.331 & 0.069 & 0.016 & 0.581 \\
\hline Whale/dolphin watching & 4.1 & 1.196 & 0.256 & 0.590 & -0.013 & 0.326 & 0.053 & 0.522 \\
\hline Visit the outback & 3.73 & 1.292 & 0.496 & 0.589 & 0.086 & 0.202 & 0.073 & 0.646 \\
\hline Eat out at a restaurant/cafe & 3.87 & 1.22 & 0.064 & 0.577 & 0.290 & 0.012 & 0.506 & 0.678 \\
\hline Botanical/public gardens & 3.47 & 1.351 & 0.359 & 0.502 & 0.035 & 0.299 & 0.340 & 0.586 \\
\hline Visit reservation parks & 3.69 & 1.352 & 0.348 & 0.487 & -0.050 & 0.441 & 0.207 & 0.599 \\
\hline Leisure activities & 3.12 & & & & & & & \\
\hline Casinos & 2.66 & 1.506 & 0.157 & 0.079 & 0.786 & 0.187 & 0.062 & 0.688 \\
\hline Pubs/clubs/discos & 3.11 & 1.467 & 0.147 & 0.106 & 0.733 & 0.225 & 0.182 & 0.653 \\
\hline Organized sporting events as spectator & 2.94 & 1.496 & 0.223 & 0.049 & 0.699 & 0.076 & 0.146 & 0.567 \\
\hline Wineries & 3.55 & 1.335 & 0.252 & 0.384 & 0.517 & 0.136 & 0.269 & 0.569 \\
\hline Guided tours/excursions & 3.33 & 1.397 & 0.268 & 0.453 & 0.458 & 0.065 & 0.158 & 0.515 \\
\hline Water-based activities & 3.70 & & & & & & & \\
\hline Swimming & 3.81 & 1.411 & -0.007 & 0.148 & 0.167 & 0.786 & 0.169 & 0.696 \\
\hline Surfing & 3.24 & 1.593 & 0.089 & -0.011 & 0.259 & 0.772 & 0.057 & 0.675 \\
\hline Snorkeling & 3.61 & 1.472 & 0.150 & 0.132 & 0.208 & 0.732 & -0.035 & 0.62 \\
\hline Go to the beach & 4.13 & 1.254 & 0.108 & 0.327 & -0.091 & 0.580 & 0.385 & 0.612 \\
\hline Popular tourist activities 2 & 3.70 & & & & & & & \\
\hline Amusements/theme parks & 3.67 & 1.297 & 0.300 & 0.013 & 0.192 & 0.118 & 0.736 & 0.683 \\
\hline Zoo/aquariums & 3.68 & 1.273 & 0.259 & 0.198 & 0.169 & 0.156 & 0.735 & 0.699 \\
\hline Shopping for pleasure & 3.76 & 1.308 & 0.035 & 0.344 & 0.345 & 0.206 & 0.547 & 0.58 \\
\hline Variance extracted (total 62.691) & & & 15.072 & 13.857 & 11.786 & 11.100 & 10.875 & \\
\hline Eigenvalues & & & 3.768 & 3.464 & 2.946 & 2.775 & 2.719 & \\
\hline
\end{tabular}

Extraction method: Principle components; Rotation method: Varimax with Kaiser normalization; Rotation converged in 13 iterations. Kaiser-Meyer-Olkin measure of sampling adequacy $=0.91$; Bartlett's test of sphericity: $x^{2}(300)=4331.113$, sig. $=0$.

historic/monuments, and theme park visits. More physically challenging and active activities (i.e., snorkeling, bush walking, and surfing) were the less appealing activities. There were two items with means below 3: "organized sporting events as a spectator" and "casinos."

Exploratory factor analysis (EFA) was performed to investigate any underlying dimensions that could indicate commonalities among the activities. The Kaiser-Meyer-Olkin test $(\mathrm{KMO}=0.910)$ and Bartlett's Test of Sphericity $\left[x^{2}(300)=4331.113\right.$, sig. $=0$ ] confirmed sample adequacy and validity of the correlation matrix. Results indicated a fivefactor solution, explaining $62.691 \%$ of total variance. Within the five factors, all factor loadings of the items upon their specific factors surpassed 0.45. The five factors were named "cultural activities," "popular tourist activities 1," "leisure activities," "water-based activities," and "popular tourist activities 2." Using summated scores, the most popular group of activities were the "popular tourist activities 1" and the least popular group was "leisure activities.”

\section{Interests in Types of Events}

Respondents were then asked to indicate their interests in different types of events should they choose to attend one while traveling in Australia. Their level of interest was analyzed using mean 
Table 3

Type of Events: EFA

\begin{tabular}{|c|c|c|c|c|c|c|}
\hline & Mean & $S D$ & $\begin{array}{c}\text { Factor } \\
\text { Loadings }\end{array}$ & 1 & 2 & Communalities \\
\hline Free sport events & 2.61 & & & & & \\
\hline Free event/running & 2.48 & 1.375 & 0.790 & 0.153 & 0.371 & 0.785 \\
\hline Free event/other sports & 2.67 & 1.336 & 0.778 & 0.231 & 0.234 & 0.713 \\
\hline Free event/golf & 2.45 & 1.39 & 0.767 & 0.221 & 0.308 & 0.732 \\
\hline Free event/cricket/football & 2.56 & 1.415 & 0.766 & 0.172 & 0.322 & 0.720 \\
\hline Free event/tennis & 2.88 & 1.5 & 0.758 & 0.221 & 0.169 & 0.651 \\
\hline Cultural events & 3.36 & & & & & \\
\hline Free event/cultural festival & 3.64 & 1.34 & 0.334 & 0.847 & -0.028 & 0.829 \\
\hline Free event/music concert & 3.48 & 1.377 & 0.404 & 0.804 & 0.039 & 0.810 \\
\hline Free event/food and wine festival & 3.89 & 1.335 & 0.229 & 0.751 & 0.065 & 0.621 \\
\hline Ticketed/music concert & 2.93 & 1.42 & 0.099 & 0.679 & 0.479 & 0.700 \\
\hline Ticketed/cultural festival & 2.90 & 1.407 & 0.096 & 0.665 & 0.533 & 0.735 \\
\hline Ticketed/food and wine festival & 3.31 & 1.468 & -0.080 & 0.663 & 0.493 & 0.689 \\
\hline Ticketed sport events & 2.26 & & & & & \\
\hline Ticketed/golf & 2.22 & 1.269 & 0.408 & 0.180 & 0.742 & 0.75 \\
\hline Ticketed/cricket/football & 2.21 & 1.306 & 0.433 & 0.129 & 0.724 & 0.729 \\
\hline Ticketed/running & 2.26 & 1.327 & 0.409 & 0.127 & 0.715 & 0.695 \\
\hline Ticketed/sport & 2.33 & 1.358 & 0.490 & 0.131 & 0.675 & 0.713 \\
\hline Variance extracted (total 72.489) & & & 27.277 & 23.701 & 21.510 & \\
\hline Eigenvalues & & & 4.092 & 3.555 & 3.227 & \\
\hline
\end{tabular}

Extraction method: Principle components; Rotation method: Varimax with Kaiser normalization; Rotation converged in 9 iterations. Kaiser-Meyer-Olkin measure of sampling adequacy $=0.878$; Bartlett's test of sphericity: $x^{2}(105)=3917.028$, sig. $=0$.

values and EFA (Table 3). It was very clear from the mean scores that cultural events were more popular than sporting events, and theme was confirmed as a relevant dimension in the EFA with all cultural events loading onto a single factor. A three-factor solution was derived, explaining $72.5 \%$ of the total variance. The three factors were identified as "free sport events," "cultural events," and "ticketed sport events." The solution indicated very clearly that the respondents of this research distinguished types of events primarily by theme, but that price was also an issue for less desirable experiences. All cultural events (both free and ticked events) had a mean value higher than any sporting event, with almost all cultural events above the midpoint of 3 and all sporting events below 3 . This is in consistent with the results shown in Table 2, in which cultural activities were ranked higher than viewing sport events as spectators with regard to participation intention. This suggests that overall, Chinese tourists are more interested in cultural events than sports events. However, to investigate the homogeneity of the sample, a cluster analysis was undertaken to explore subgroups based on event interest.

\section{Cluster Analysis}

In order to better understand the differing interests of Chinese tourists in events, a cluster analysis was undertaken using respondents' ratings of their level of interest in different types of events. Although it is somewhat common in tourism research to cluster on factor scores, there is evidence that this does not lead to the best cluster solutions (Dolnicar \& Grun, 2008). This is because factor analysis is summarizing based on similarities in the sample, while cluster analysis is looking for differences. A large proportion of the variance in the data set is usually lost in the factor solution. Thus, the critical differences between respondents may be ignored.

The analysis was of the hierarchical type, as there was no previous research that could assist in determining the appropriate number of clusters. Ward's method was used with squared Euclidean distances as the measure. A range of solutions was explored, starting with the simplest two-cluster solution, and proceeding up to a five-cluster solution. There are no reliable measures on which to base the selection of one cluster solution over another. As Jurowski 
and Reich (2000) suggested, the technique can be "considered an art as well as a science" (p. 69). Therefore, the decision to select one solution is often based on how useful and interpretable it is compared to others (L. Fredline, 2012). The threecluster solution was selected because it provided a good delineation between levels of interest in different event types.

Cluster 1 has been labeled as Cultural Event Tourists because this group rated their interest in cultural events most highly as shown in Table 4 . All cultural event types were rated, on average, above the midpoint of the scale, with free events rated more highly than ticketed events. One sport event type, a free tennis event was rated above the midpoint as well. This cluster contained 111 respondents or $33.1 \%$ of the sample.

Cluster 2 has been described as Free Event Tourists. Their rating of interest for all events was above the midpoint, but all of the free events were rated more highly than any of the ticketed events. This group was the smallest containing only $14.6 \%$ of the sample.

Cluster 3 has been described as Nonevent Tourists as their level of interest in almost all events was lower than the midpoint on the scale. The only event they rated above 3 was free food and wine festivals. They did demonstrate higher levels of interest in cultural events than sporting events. This group comprised $52.2 \%$ of the sample.

In an effort to better understand the clusters, membership in each group was cross-tabulated with a range of demographic and travel history variables as shown in Table 5. There were no significant relationships between gender, age, or employment status and cluster membership, but a pattern was observed with regard to previous travel history.

Respondents who had never traveled overseas before were more likely to be in cluster 3 , which has the least interest in attending events, while those who had traveled overseas two to five times previously where significantly more likely to be in cluster 2, which had the highest level of interest in events. Cluster 1 contains a higher proportion of people who had traveled 6 or more times. This suggests that first time travelers are less likely to be interested in events, perhaps because they are more oriented toward iconic attractions and general sightseeing on their first trip. Similarly, people who had previously visited Australia were most likely to be in Cluster 1, and therefore be most interested in cultural events.

Although there is a tendency across all clusters to prefer cultural events and to prefer free events, there is a subgroup who would rather attend a free sport event than a ticket cultural event.

Table 4

Mean Event Interest by Cluster Membership

\begin{tabular}{llllll}
\hline $\begin{array}{l}\text { Cluster 1: Cultural Event Tourists } \\
(n=111)\end{array}$ & & \multicolumn{1}{c}{$\begin{array}{c}\text { Cluster 2: Free Event Tourists } \\
(n=49)\end{array}$} & & \multicolumn{2}{c}{$\begin{array}{c}\text { Cluster 3: Nonevent Tourists } \\
(n=175)\end{array}$} \\
\hline Free event/food and wine festival & 4.41 & Free event/food and wine festival & 4.88 & Free event/food and wine festival & 3.27 \\
Free event/cultural festival & 4.27 & Free event/tennis & 4.82 & Free event/cultural festival & 2.93 \\
Free event/music concert & 4.17 & Free event/cultural festival & 4.73 & Ticketed/food and wine festival & 2.70 \\
Ticketed/food and wine festival & 3.96 & Free event/music concert & 4.73 & Free event/music concert & 2.69 \\
Ticketed/cultural festival & 3.60 & Free event/cricket/football & 4.69 & Ticketed/music concert & 2.21 \\
Ticketed/music concert & 3.58 & Free event/running & 4.69 & Ticketed/cultural festival & 2.15 \\
Free event/tennis & 3.48 & Free event/golf & 4.65 & Free event/other sports & 1.98 \\
Free event/cricket/football & 2.89 & Free event/other sports & 4.61 & Free event/tennis & 1.96 \\
Free event/other sports & 2.89 & Ticketed/food and wine festival & 4.00 & Free event/cricket/football & 1.75 \\
Free event/golf & 2.84 & Ticketed/music concert & 4.00 & Free event/running & 1.74 \\
Ticketed/sport & 2.77 & Ticketed/cultural festival & 3.94 & Ticketed/running & 1.61 \\
Free event/running & 2.67 & Ticketed/sport & 3.94 & Ticketed/sport & 1.60 \\
Ticketed/running & 2.62 & Ticketed/golf & 3.84 & Free event/golf & Ticketed/golf \\
Ticketed/golf & 2.53 & Ticketed/cricket/football & 3.80 & Ticks \\
Ticketed/cricket/football & 2.52 & Ticketed/running & 3.73 & Ticketed/cricket/football & 1.57 \\
\hline
\end{tabular}


Table 5

Travel History by Cluster Membership

\begin{tabular}{|c|c|c|c|c|}
\hline & $\begin{array}{l}\text { Cluster 1: Cultural } \\
\text { Event Tourists }\end{array}$ & $\begin{array}{l}\text { Cluster 2: Free } \\
\text { Event Tourists }\end{array}$ & $\begin{array}{c}\text { Cluster 3: } \\
\text { Nonevent Tourists }\end{array}$ & $\begin{array}{c}\text { Overall } \\
\text { Percentage }\end{array}$ \\
\hline \multicolumn{5}{|c|}{ Previous travel history $\left[\chi^{2}(6)=19.86, p<0.05\right]$} \\
\hline Never traveled overseas before & $22.3 \%$ & $14.3 \%$ & $36.1 \% \uparrow$ & $28.1 \%$ \\
\hline One trip overseas & $17.5 \%$ & $14.3 \%$ & $20.9 \%$ & $18.7 \%$ \\
\hline $2-5$ trips & $45.6 \%$ & $63.3 \% \uparrow$ & $36.7 \%$ & $43.9 \%$ \\
\hline 6 or more trips & $14.6 \%$ & $8.2 \%$ & $6.3 \%$ & $9.4 \%$ \\
\hline \multicolumn{5}{|c|}{ Been to Australia before $\left[\chi^{2}(2)=12.28, p<0.05\right]$} \\
\hline No & $70.8 \%$ & $83.7 \%$ & $87.7 \%$ & $81.4 \%$ \\
\hline Yes & $29.2 \% \uparrow$ & $16.3 \%$ & $12.3 \%$ & $18.6 \%$ \\
\hline
\end{tabular}

Note. Percentages are reported within columns. $\uparrow$ denotes significantly higher proportion than expected.

\section{Awareness of Specific Events}

Table 6 reports the results of respondents' level of interest in attending 13 specified Australian events. An option of "don't know" was provided in the questionnaire and this was counted as zero in the 5-point Likert scale for this analysis. Therefore, the mean values for level of interest in the 13 events were generally not high. Thus, median and mode values were also provided, which might work as a better indication for respondents' interests.

The results shown in Table 6 at first appear to be inconsistent with the results already reported in that the three highest ranked events are all sporting events, which were generally rated as less interesting to Chinese tourist than cultural events. However, this simply highlights the emphasis placed on sport in the Australian event context. There were very few hallmark cultural events that could be included as

Table 6

Level of Interests and Mean Values: The Events

\begin{tabular}{lccc}
\hline & Mean & Median & Mode \\
\hline Tour Down Under/cycling & 3.43 & 4.00 & 5 \\
Australian Open Tennis & 3.39 & 4.00 & 5 \\
Melbourne Cup/Horse Race & 3.13 & 3.00 & 5 \\
Sydney RES & 3.04 & 3.00 & 5 \\
Formula 1 Grand Prix & 2.78 & 3.00 & 5 \\
Melbourne Comedy Festival & 2.72 & 3.00 & 5 \\
GC 600 Motor Race & 2.71 & 3.00 & 5 \\
New Year's fireworks & 2.70 & 3.00 & 5 \\
Open of Surfing & 2.70 & 3.00 & 3 \\
Flower festival & 2.56 & 3.00 & 3 \\
GC marathon & 2.36 & 2.00 & 3 \\
Surf Fun Run & 2.26 & 2.00 & 1 \\
NYE Sydney Fireworks & 2.24 & 2.00 & 1 \\
\hline
\end{tabular}

named events in the questionnaire. Thus, the three most highly rated named events-Tour Down Under/Cycling, The Australian Open Tennis, and the Melbourne Cup/Horse Race-are all events that may be recognizable to Chinese respondents. The first two events were widely live broadcasted on Chinese television and usually have popular Chinese players (e.g., $\mathrm{Li} \mathrm{Na}$ is a popular Chinese female tennis player) competing in the events. The Melbourne Cup, although technically a sporting event, also has a cultural dimension. Horse Race events might be particularly appealing to people who live in Guangdong Province, due to the influence of the Hong Kong Jockey Club horse races.

The highest ranked cultural event was the Sydney Royal Easter Show. Although this event has many attractions that incorporate elements of activities that were highly rated (e.g., displays of farm animals and aboriginal culture), it is unlikely that many Chinese tourists would have a thorough understanding of this event.

There were some differences identified between the clusters in terms of the specified events ratings. Although cultural event tourists have the same overall ranking as the entire sample, free event tourist actually rated New Year's fireworks as the most interesting event, and nonevent tourists prioritized the Sydney Royal Easter Show over the Melbourne Cup as shown in Table 7.

\section{Barriers to Attendance}

Finally, exploratory factor analysis was performed to identify issues that hinder Chinese tourists from 
Table 7

Specific Events by Cluster

\begin{tabular}{|c|c|c|c|c|c|}
\hline \multicolumn{2}{|c|}{ Cluster 1: Cultural Event Tourists } & \multicolumn{2}{|c|}{ Cluster 2: Free Event Tourists } & \multicolumn{2}{|c|}{ Cluster 3: Nonevent Tourists } \\
\hline Tour Down Under/cycling & 4.23 & New Year's Fireworks & 4.38 & Tour Down Under/cycling & 3.39 \\
\hline Australian Open Tennis & 4.15 & Australian Open Tennis & 4.32 & Australian Open Tennis & 3.28 \\
\hline Melbourne Cup/Horse Race & 3.98 & Melbourne Cup/Horse Race & 4.24 & Sydney RES & 3.03 \\
\hline
\end{tabular}

event attendance in their overseas trips (Table 8). The issues were measured on a 5-point scale ranging from 1 = "I would not want to attend" to $5=$ "I would still like to attend," so a higher mean indicates less of a barrier. The result was a two-factor solution, explaining $59.084 \%$ of the total variances. The two factors were labeled "cultural barriers" and "inconveniences." Overall, cultural barriers seemed to be more important, with a "not interested in theme of event" (2.31) and "not understanding the rules" (2.35) of the game appearing to put Chinese tourists off. Among the inconveniences, "ticket very expensive" (mean $=2.35$ ) was the most serious barrier while some of the other inconveniences such as "no Chinese food onsite" (mean = 3.08) and "event outside a main city" (mean $=2.93$ ), were less of an issue for participation. In general, it was "cultural barriers" that potentially hindered the attendance in Australian events most.

To further examine the differences for each cluster, the barriers to attendance by cluster are reported in
Table 9. For cluster 3, the nonevent tourists, all of these constraints lead them to report in the lower half of the scale, that they generally did not want to attend. However, this is understandable as they had very little interest in events anyway. For cluster 1 , the most important barriers were still the cultural barriers. However, for cluster 2, the biggest barrier seems to be price of ticket which is consistent with their preference for free events.

\section{Discussion and Conclusion}

This study has explored the attractiveness of Australian events to Chinese tourists. This is already a very important source market for Australian tourism and, as it grows, it would be advantageous for Australian events to be able to boost their profitability by attracting more Chinese visitors. The results appear to suggest that events do not currently feature highly in attractiveness when compared to other Australian attractions, in particular the beach,

Table 8

Barriers to Attend: EFA

\begin{tabular}{llllll}
\hline Barriers to Attend & Mean & SD & Factor Loadings & Communalities \\
\hline Cultural barriers & $\mathbf{2 . 4 8}$ & & & & \\
$\quad$ Not interested in theme of events & 2.31 & 1.348 & $\mathbf{0 . 8 8 6}$ & 0.115 & 0.798 \\
$\quad$ Not know the theme of the events & 2.39 & 1.342 & $\mathbf{0 . 8 6 9}$ & 0.180 & 0.787 \\
Not understand rules of games & 2.35 & 1.327 & $\mathbf{0 . 8 6 6}$ & 0.204 & 0.791 \\
$\quad$ Not know Western music/culture & 2.86 & 1.318 & $\mathbf{0 . 6 3 5}$ & 0.324 & 0.508 \\
Inconveniences & $\mathbf{2 . 7 2}$ & & & & \\
$\quad$ No Chinese food onsite & 3.08 & 1.397 & -0.071 & $\mathbf{0 . 8 1 8}$ & 0.675 \\
Event outside a main city & 2.93 & 1.263 & 0.214 & $\mathbf{0 . 7 2 1}$ & 0.566 \\
$\quad$ No help with not speak English & 2.61 & 1.363 & 0.254 & $\mathbf{0 . 6 8 6}$ & 0.535 \\
Inconvenient timing & 2.6 & 1.297 & 0.462 & $\mathbf{0 . 5 7 4}$ & 0.544 \\
$\quad$ Take too long to participate & 2.6 & 1.3 & 0.502 & $\mathbf{0 . 5 4 9}$ & 0.553 \\
$\quad$ Ticket very expensive & 2.32 & 1.326 & 0.257 & $\mathbf{0 . 5 0 7}$ & 0.323 \\
$\quad$ Not included in package tour itinerary & 2.9 & 1.321 & 0.458 & $\mathbf{0 . 4 5 8}$ & 0.419 \\
Variance extracted (total 59.084) & & & 32.259 & 26.825 & \\
Eigenvalues & & & 3.549 & 3.549 & \\
\hline
\end{tabular}

Extraction method: Principal component analysis; Rotation method: Varimax with Kaiser normalization; Rotation converged in 3 iterations. Kaiser-Meyer-Olkin measure of sampling adequacy $=0.868$; Bartlett's test of sphericity: $\chi^{2}(55)=1606.442$, sig. $=0$. 
Table 9

Barriers to Event Attendance by Cluster

\begin{tabular}{llllll}
\hline Cluster 1: Cultural Event Tourists & \multicolumn{2}{c}{ Cluster 2: Free Event Tourists } & & \multicolumn{2}{c}{ Cluster 3: Nonevent Tourists } \\
\hline Not interested in theme of events & 2.50 & Ticket very expensive & 2.76 & Not understand rules of games & 1.99 \\
Not understand rules of games & 2.59 & Inconvenient timing & 2.92 & Ticket very expensive \\
Not know the theme of the events & 2.62 & Not know the theme of the events & 2.96 & Not interested in theme of events & 2.02 \\
Ticket very expensive & 2.72 & Not interested in theme of events & 2.98 & Not know the theme of the events & 2.09 \\
Inconvenient timing & 2.89 & Take too long to participate & 2.98 & Take too long to participate & 2.29 \\
No help with not speak English & 2.94 & Not understand rules of games & 3.02 & No help with not speak English \\
Take too long to participate & 3.01 & No help with not speak English & 3.16 & Inconvenient timing \\
Not know western music/culture & 3.13 & Event outside a main city & 3.24 & Not know western music/culture & 2.51 \\
Not included in package tour & 3.26 & Not included in package tour & 3.33 & Not included in package tour & 2.58 \\
$\quad$ itinerary & & itinerary & & itinerary & \\
Event outside a main city & 3.33 & Not know western music/culture & 3.59 & Event outside a main city \\
No Chinese food onsite & 3.53 & No Chinese food onsite & 3.67 & No Chinese food onsite \\
\hline
\end{tabular}

city sightseeing, and animal based attractions such as whale watching. However, Chinese tourists do express high levels of interest in cultural activities and attractions, and festivals and cultural events seem to capture their attention, at least in theory with a mean interest rating of 3.8 on a 5-point scale. Perhaps the problem is that most festivals and cultural events are small scale and lack the resources to promote themselves extensively to an international market. Thus, awareness of specific festival and cultural events within the Chinese tourist market is low.

A breakdown of the overall sample using cluster analysis showed that there are differences in the level of interest and type of events and results suggest that interest in events tends to grow with international travel experience. This is promising as it suggests that interest in Australian events will continue to grow as Chinese tourists gain more travel experience.

Generally speaking, the Chinese tourists did not report high levels of interest in sport events. However, that there are some specific sport events, particularly those with prominent Chinese participants, for example the Australian Tennis Open, which were identified as being of interest to Chinese tourists. Perhaps as these and other Western sports become more popular in China, there will be more interest as the cultural barriers diminish.

The results of this research may be valuable for the tourism and events industry. The level of interest in events identified in this study does not imply that many Chinese tourists visit Australia to attend events as their primary motive. However, it is clearly possible that events could be a peripheral attraction for these visitors, which complements McKercher et al.'s (2006) view on integrating events into the tourism attraction system. The events that are of most interest to Chinese tourists are smaller festivals and cultural events that often lack the resources for expensive promotion in international markets. Therefore, bundling festivals and promoting them collectively as a distinct product could raise the profile of all participating festivals. Campaigns by destination management organizations could promote the event attendance experience, rather than promoting any single event. Thus, increasing the probability of attracting more tourists to all cultural events.

The biggest barriers identified for event attendance were the cultural barriers, consistent with Lepisto and Hannaford (1980), such as not understanding or being interested in the theme of event. This is most likely particularly true of events based on sports that are not popular in China. However, China's perspectives continue to broaden and their participation in a range of sports will no doubt increase over time. For example, in $2013 \mathrm{Ji}$ Cheng became the first Chinese cyclist to complete in the Giro D'Italia cycling event, and then in 2014 he also competed in the Tour De France. This study identified the Tour Down Under as the most interesting named event, perhaps because of a growing interest in cycling brought about by the success of this Chinese athlete. By extension, it may be possible to attract more Chinese tourists to Australian sporting events by identifying and promoting the success of Chinese participants. 
The results of the study imply that any increase in interest in Australian events from the Chinese inbound market will likely be slow as Chinese tourists gain international travel experience. However, given the size of this potential market, even a small increase in demand could result in a large increase in the number of visitors. In order to maximize the potential of this growth, event organizers should work in conjunction with destination marketing groups (both national and state level) to highlight event opportunities that fit well into itinerates that also include the other important activities that Chinese tourists wish to engage in. For example, city sightseeing was rated as a highly important activity, and free food and wine events were rated as the most attractive. There are numerous small free-entry food and wine events hosted around the capital cities of Australia at attractive tourist sites, for example, Southbank in Brisbane. However, these events do not appear on the TA website and often not on the state marketing websites either. Therefore, it is virtually impossible for Chinese visitors to know about these events unless they chance upon them when they happen to be in the vicinity. Therefore, it would be useful for these small events to work in conjunction with destination marketing bodies to resolve this deficiency. Similarly, state and national DMOs should incorporate visits to events that appeal to Chinese visitors into familiarization trips for Chinese travel agents. Other barriers identified included a range of inconveniences such as time, money, and travel distance, which is consistent with previous research (Boo et al., 2014; Milner et al., 2004); however, these were generally perceived as lesser barriers than the cultural issues.

It is important to acknowledge the limitations of the research. In this case the data were collected by third party travel agents using a self-completion questionnaire. Therefore, the researcher or trained interviewers were not available to clarify any misunderstandings or ensure all questions were completely answered. Missing data can constitute a form of response bias; however, in this case the incidence of missing data was relatively small.

This study was highly exploratory, and the results highlight the need for further research on the very important Chinese tourism market. Festivals and cultural events is a broad category so it would be interesting to further breakdown the elements of events that are most interesting to Chinese tourists. The most highly rated type of event was a free food and wine festival, so it would be interesting to further what type of food would interest visitors. As it appears that events are primarily a peripheral attraction, it is important to understand the travel patterns of Chinese tourists within Australia, so that it is possible to identify which events are most likely to be patronized and maximize their accessibility. Chinese tourists also expressed a strong preference for free events and concern about ticket price as a barrier so it would be useful to explore price points that may acceptable to this market.

\section{References}

Axelsen, M. (2006). Using special events to motivate visitors to attend art galleries. Museum Management and Curatorship, 21(3), 205-221.

Boo, S., Carruthers, C. P., \& Busser, J. A. (2014). The constraints experienced and negotiation strategies attempted by nonparticipants of a festival event. Journal of Travel \& Tourism Marketing, 31(2), 269-285.

Bowen, H. E. \& Daniels, M. J. (2005). Does the music matter? Motivations for attending a music festival. Event Management, 9(3), 155-164.

Chalip, L., Green, B. C., \& Hill, B. (2003). Research and reviews. Journal of Sport Management, 17, 214-234.

Chan, G. S. H. (2015). Perceived impact of hosting a sport event in a destination: A case study of the Hong Kong Rugby Sevens. Journal of Management and Sustainability, 5(3), 49-60.

China Tourism Academy. (2014). Annual report of China outbound tourism development. Beijing, China: Author.

Crompton, J. L., \& McKay, S. L. (1997). Motives of visitors attending festival events. Annals of Tourism Research, 24(2), 425-439.

De Bres, K., \& Davis, J. (2001). Celebrating group and place identity: A case study of a new regional festival. Tourism Geographies, 3(3), 326-337.

Deery, M., Jago, L., \& Fredline, L. (2004). Sport tourism or event tourism: Are they one and the same? Journal of Sport and Tourism, 9(3), 235-245.

Deery, M., Jago, L., \& Fredline, L. (2012). Rethinking social impacts of tourism research: A new research agenda. Tourism Management, 33(1), 64-73.

Dewar, K., Meyer, D., \& Li, W. M. (2001). Harbin, lanterns of ice, sculptures of snow. Tourism Management, 22(5), 523-532.

Dolnicar, S., \& Grun, B. (2008). Challenging "factor-cluster segmentation.” Journal of Travel Research, 47(1), 63-71.

Dwyer, L., Mellor, R., Mistilis, N., \& Mules, T. (2000). A framework for assessing "tangible" and "intangible" impacts of events and conventions. Event Management, 6(3), 175-189. 
Fredline, E., \& Faulkner, B. (2000). Host community reactions: A cluster analysis. Annals of Tourism Research, 27(3), 763-784.

Fredline, L. (2012). Cluster analysis. In L. Dwyer, A. Gill, N. Seetaram (Eds.), Handbook of research methods in tourism: Quantitative and qualitative approaches (pp. 212226). Cheltenham, UK: Edward Elgar.

Fredline, L., Jago, L., \& Deery, M. (2003). The development of a generic scale to measure the social impacts of events. Event Management, 8(1), 23-37.

Funk, D. C., Alexandris, K., \& Ping, Y. (2009). To go or stay home and watch: Exploring the balance between motives and perceived constraints for major events: A case study of the 2008 Beijing Olympic Games. International Journal of Tourism Research, 11(1), 41-53.

Getz, D. (1997). Event management \& event tourism. New York, NY: Cognizant Communication Corporation.

Getz, D. (2002). Why festivals fail. Event Management, 7(4), 209-219.

Getz, D. (2008). Event tourism: Definition, evolution, and research. Tourism Management, 29(3), 403-428.

Gnoth, J., \& Anwar, S. A. (2000). New Zealand bets on event tourism. Cornell Hotel and Restaurant Administration Quarterly, 41(4), 72-83.

Guangdong's economy remains biggest, Chongqing leads growth. (2017). Chinadaily. Retrieved from http://www. chinadaily.com.cn/business/2017-02/07/content_28126256. htm

Hsu, C. H., Cai, L. A., \& Li, M. (2010). Expectation, motivation, and attitude: A tourist behavioral model. Journal of Travel Research, 49(3), 282-96.

Iso-Ahola, S. (1983) Towards a social psychology of recreational travel. Leisure Studies, 2(1), 45-56.

Jurowski, C., \& Reich, A. (2000). An explanation and illustration of cluster analysis for identifying hospitality market segments. Journal of Hospitality and Tourism Research, 24, 67-91.

Kim, K., Uysal, M., \& Chen, J. S. (2002). Festival visitor motivation from the organizers' point of view. Event Management, 7, 127-134.

Kim, S.-K., Byon, K. K., Yu, J.-G., Zhang, J. J., \& Kim, C. (2013). Social motivations and consumption behavior of spectators attending a formula one motor-racing event. Social Behavior and Personality, 41(8), 1359-1377.

Kruger, M., \& Saayman, M. (2012). Creating a memorable spectator experience at the Two Oceans Marathon. Journal of Sport \& Tourism, 17(1), 63-77.

Lee, C.-K., Lee, Y.-K., \& Wicks, B. E. (2004). Segmentation of festival motivation by nationality and satisfaction. Tourism Management, 25(1), 61-70.

Lepisto, L. R., \& Hannaford, W. J. (1980). Purchase constraint analysis: An alternative perspective for marketers. Journal of the Academy of Marketing Science, 8(1-2), 12-25.

Li, M., Zhang, H., Mao, I., \& Deng, C. (2011). Segmenting Chinese outbound tourists by perceived constraints. Journal of Travel and Tourism Marketing, 28(6), 629-643.
Li, X., Lai, C., Harrill, R., Kline, S., \& Wang, L. (2011). When East meets West: An exploratory study on Chinese outbound tourists' travel expectations. Tourism Management, 32(4), 741-749.

Li, X., \& Petrick, J. F. (2006). A review of festival and event motivation studies. Event Management, 9(4), 239-245.

Matheson, V. A. (2005). Contrary evidence on the economic effect of the Super Bowl on the victorious city. Journal of Sports Economics, 6(4), 420-428.

Mackellar, J. (2013). Event audiences and expectations. Abingdon, UK: Routledge.

McKercher, B., Mei, W. S., \& Tse, T. S. M. (2006). Are short duration cultural festivals tourist attractions? Journal of Sustainable Tourism, 14(1), 55-66.

Milner, L. M., Jago, L. K., \& Deery, M. (2004). Profiling the special event non-attendee: An initial investigation. Event Management, 8(3), 141-150.

Morgan, M. (2009). What makes a good festival? Understanding the event experience. Event Management, 12(2), 81-93.

Pegg, S., \& Patterson, I. (2010). Rethinking music festivals as a staged event: Gaining insights from understanding visitor motivations and the experiences they seek. Journal of Convention \& Event Tourism, 11(2), 85-99.

Prentice, R., \& Andersen, V. (2003). Festival as creative destination. Annals of Tourism Research, 30(1), 7-30.

Pritchard, M., Funk, D., \& Alexandris, K. (2007). Barriers to repeat patronage: The impact of spectator constraints. European Journal of Marketing, 43(1), 169-187.

Regan, N., Carlson, J., \& Rosenberger, P. J. (2012). Factors affecting group-oriented travel intention to major events. Journal of Travel \& Tourism Marketing, 29(2), 185-204.

Richards, G., \& Wilson, J. (2004). The impact of cultural events on city image: Rotterdam, cultural capital of Europe 2001. Urban Studies, 41(10), 1931-1951.

Robinson, R. N. S., \& Clifford, C. (2012). Authenticity and festival foodservice experiences. Annals of Tourism Research, 39(2), 571-600.

Robertson, M., \& Guerrier, Y. (1998). Events as entrepreneurial displays: Seville, Barcelona and Madrid. In D. Tyler, Y. Guerrier, \& M. Robertson, M. (Eds.), Managing tourism in cities-policy, process and practice (pp. 215228). Chichester, UK: John Wiley \& Sons Inc.

Santos-Lewis, R., \& Moital, M. (2013). Constraints to attend events across specialization levels. International Journal of Event and Festival Management, 4(2), 107-124.

Savinonic, A., Kim, S., \& Long, P. (2012). Audience members' motivation, satisfaction, and intention to re-visit an ethnic minority cultural festival. Journal of Travel \& Tourism Marketing, 29, 185-204.

Sparks, B., \& Pan, G. (2009). Chinese outbound tourists: Understanding their attitudes, constraints and use of information sources. Tourism Management, 30(4), 483-494.

Stokes, R. (2008). Tourism strategy making: Insights to the events tourism domain. Tourism Management, 29(2), 252-262. 
Tourism Australia. (2014). Tourism forecasts Autumn 2014 Final 18062014. Retrieved from https://www.tra.gov.au/ Research/View-all-publications/All-Publications/Forecastreports/tourism-forecasts-autumn-2014

United Nations World Tourism Organization. (2016). UNWTO tourism highlights, 2016 edition. Retrieved from http://mkt. unwto.org/publication/unwto-tourism-highlights-2016edition

Van Zyl, C., \& Botha, C. (2003). Motivational factors of local residents to attend the Aardklop National Arts Festival. Event Management, 8(4), 213-222.
Williams, M., \& Bowdin, G. A. J. (2007). Festival evaluation: An exploration of seven UK arts festivals. Managing Leisure, 12(2-3), 187-203.

Xie, P. F. (2004). Visitors' perceptions of authenticity at a rural heritage festival: A case study. Event Management, 8(3), 151-160.

Yang, F. X., \& Lau, V. M. C. (2015). “LuXurY” hotel loyaltya comparison of Chinese Gen X and Y tourists to Macau. International Journal of Contemporary Hospitality Management, 27(7), 1685-1706. 